\title{
TELEMEDICINE STRATEGY CONCEPTS IN HANDLING COVID-19 IN INDONESIA IN 2021
}

\author{
By \\ Endang Naryono \\ PASIM Economics College Lecturer \\ rtumarima@gmail.com
}

\begin{abstract}
ION
Indonesia is one of the countries where the spread of COVID-19 is one of the highest in the world with an average daily from June to July 2021 of 14,000 people who are positive for COVID-19, which so far has touched 2.3 million people with a cure rate of $84 \%$ and a mortality rate of $2.6 \%$. The increase in the number of people who are positive for COVID-19 has made the government's burden even heavier. The most crucial problem is the availability of beds, at the national level the hospital occupancy rate has been above $80 \%$ so that many hospitals are no longer accepting COVID-19 patients, limited oxygen and health workers are obstacles that must be addressed as soon as possible. The government's policy of implementing an emergency PSBB on the island of Java as a solution in reducing the positive Covid-19 has been effective, although there are still many weaknesses that must be evaluated. Emergency policies to deal with covid-19 patients who cannot be handled by hospitals using the concept of telemedicine with patients being treated at home by being provided with online consultation facilities, drugs ordered and delivered for free through online media, this concept is considered the most effective in an emergency pandemic case. this covid-19.
\end{abstract}

Keywords: Telemedicine.

\section{INDONESIAN COVID-19 OVERVIEW}

The surge in Covid-19 patients during July 2021 rose sharply, the positive number of covid had touched 2.34 million people with an active case ratio of 324.6 thousand people, the cure rate ratio fell from $90 \%$ to $83.5 \%$, the death ratio dropped from $2.7 \%$ to $2.4 \%$ this phenomenon resulting in multidimensional problems in handling cases due to COVID-19. From economic, political to social. One of the most crucial problems is the lack of beds and lack of oxygen for medical purposes, the increasing number of COVID-19 cases in Indonesia, while the limited occupancy capacity has resulted in full occupancy of hospitals. In general, hospitals can no longer accept COVID19 patients due to limited inpatient facilities. This situation will be very dangerous if not addressed immediately because it will result in patients not being handled properly and will result in a high mortality ratio.

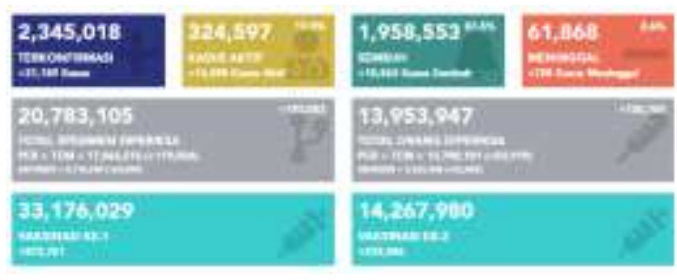

Table. 1 


\section{Distribution of Indonesian Covid-19 Cases}

Source: https://covid19.go.id/petasebaran-covid19

The national vaccination program has been running, it's just that it is still far from the expectation of the target of 180.4 million people who will be vaccinated until July 2021, only reaching 33.1 million people or below $20 \%$, the slowness of vaccination is due to several things from budget constraints, limited number of vaccines, infrastructure that is not evenly distributed to education and socialization which is still weak so that there are still many people who are not ready to be vaccinated.

Positive cases of covid-19 in July were the highest for 2 years and even one of the highest in the world, which caused a high number of positive cases of covid19. A national holiday for religious holidays where people return to their hometowns, causing mass crowds, even though the government has prohibited it, but still the flow of people's mobility from cities to villages is very high, the scale of rapid tests carried out is high so that the higher the Covid-19 detection rate, the more tired and people are fed up with the situation for 2 years, where life is getting more difficult even if it's just to survive, state aid is only temporary and not continuous so people are forced to make a living with the risk of being exposed to covid-19 and government policies that use two legs on one side focus on handling covid -19 but on the other hand the economy wants to move so there is overlapping policies, for example traditional markets, malls are still open with low health protocols and less strict sanctions from law enforcement officials. These variables greatly affect the positive rate of Covid19 in Indonesia.

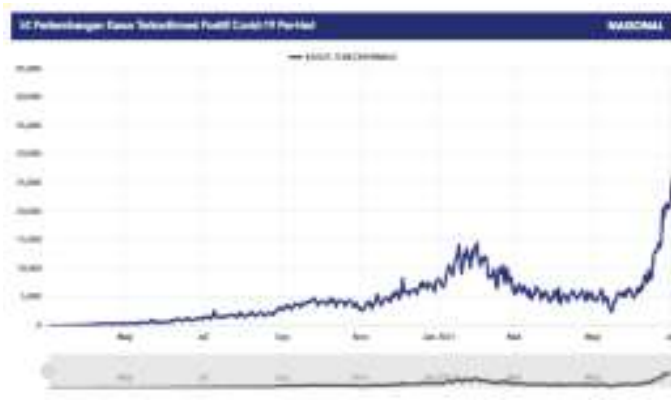

Table.2

Progress of Covid-19 Cases Per Day

2021

Source: https://covid19.go.id/petasebaran-covid19

The presentation of the number of Covid-19 cases per day in Indonesia during May to July 2021 experienced a significant increase and peaked in June and July where the average daily case reached 14 thousand people with a death ratio of $2.6 \%$ which is the highest case in the world. The high mortality ratio in Indonesia is due to the low number of rapid tests so that they cannot be detected early and can be treated early. No risk exposed is the elderly who have congenital diseases so that they have a high mortality rate. The ratio of death by age is almost the same between men and women, only by age, 50 years and over is the highest.

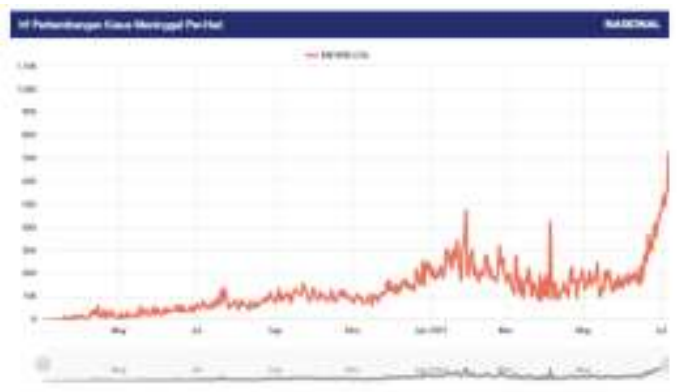

Table. 3 


\section{Indonesian Covid-19 Death Case}

Source: https://covid19.go.id/petasebaran-covid19

The sharp rise in COVID-19 during June - July 2021, correlated with the increase in the death ratio which rose but was not followed by an increase in the recovery ratio of Covid-19 patients in Indonesia. This has resulted in full hospital inpatient occupancy rates and no longer able to accept COVID-19 cases. The occupancy rate that is no longer acceptable due to the limitations of hospitals, this has also resulted in the depletion of medical oxygen supplies, and resulted in a sharp rise in the prices of Covid-19 drugs, of course the law of supply and demand applies, this will certainly burden the community and government .

The Emergency PSBB on Java Island, which took effect in early July, is one of the policies carried out by the current government. This policy was carried out against the backdrop of a sharp rise in Covid-19 cases in Indonesia, one of which was on the island of Java, which had the largest national number of cases out of four provinces on the island of Java. The emergency PSBB carried out by carrying out very strict social restrictions for the community from work activities, interaction activities to curfews that use all currently available resources, the success of this emergency PSBB absolutely must be successful because otherwise it will result in a frightening humanitarian disaster, namely The increase in Covid-19 cases but the availability of full inpatient capacity will result in an increase in the death ratio, which currently has reached
$2.6 \%$ or around 61.8 thousand people have died.

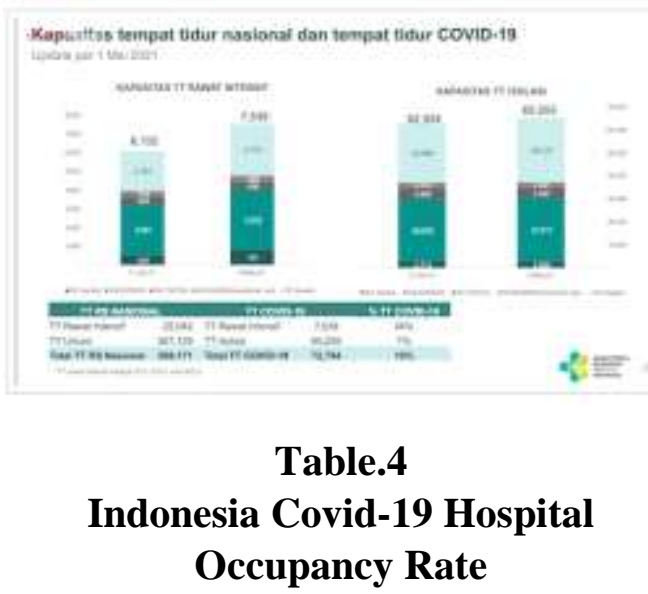

Source:

https://www.kemkes.go.id/article/view/ 21051100001/anticipation-lonjakancase-pasca- Lebaran-kemenkes-addkapasitas-place-tidur-rs.html

Seeing the data on the development of previous cases that there is always a trend of spikes in COVID-19 cases after the long holiday, the government through the Ministry of Health is preparing to take a number of anticipatory steps by recording all bed capacities in all health facilities in Indonesia, collecting data on pharmaceuticals and medical devices and providing strict assistance to regions. which indicated an increasing trend of cases. With prepare for the worst conditions, but the increase in transmission is anticipating to be prepared for unforeseen circumstances. Overall, based on data compiled by the Ministry of Health, the number of beds available is 390,000 units, of which 70,000 are used for COVID-19 services. Currently, the bed occupancy rate for COVID-19 patients is around 23 thousand. Meanwhile, for the ICU room, nationally there are around 22,000, which are designated for COVID-19 as 
many as 7,500 units. With an ICU occupancy rate of about 2,500. The capacity of the hospitals and ICUs that we have is still 3 times larger than the one we dedicate to COVID-19. From this calculation, it is estimated that there will still be up to 2 times the availability of beds to anticipate if at any time there is a spike in COVID-19 cases, especially due to the 2021 Eid holiday.

If there is a shortage of demand for beds or ICUs, you must immediately relax by converting the hospital into a special COVID-19 hospital. A number of preparations must be made immediately, just in case the preparations are not used and remain empty, but if there are at least we have made preparations. In addition to preparing for the availability of hospital beds nationally, the Ministry of Health must also monitor the bed capacity for COVID-19 patients. 19 in all regions, especially areas that have experienced a significant increase in cases in recent times. All regional heads take part in taking anticipatory and preventive steps so that there will not be a high increase in COVID-19 cases after the long Eid holiday.

There are 8 areas that indicate an increase in the occupancy of treatment rooms and special ICU rooms for COVID-19 including North Sumatra, Riau Islands, Riau, South Sumatra, Jambi, West Kalimantan, Lampung and East Nusa Tenggara. Some provinces have much higher cases, this is something that the central government should pay attention to and the local government should pay attention to. Governors, Regents and Mayors must be mature in drafting a planning concept for handling the increase in Covid-19 cases. Besides actively collecting data on hospital capacity, the Ministry of Health must strive to maintain the availability of medicines and oxygen throughout the country so that there are no vacancies. Even if there is a shortage, the region should be able to immediately update it to the Ministry of Health so that efforts can be made to immediately fulfill it.

\section{Limited Medical Oxygen Availability Capacity}

The Ministry of Industry as a stakeholder must make a policy for oxygen gas producers that $100 \%$ of their production capacity must shift their production for medical needs. Through this obligation, there are 1,700 tons of oxygen per day nationally. A total of 1,400 tons for the island of Java. Small oxygen industries have also begun to be mobilized to convert their gas production to pharmaceutical oxygen. In addition, several companies also sent iso tanks for handling oxygen supplies. Maximizing the available oxygen industry resources, such as 21 units of 20 ton ISO tank capacity from the Indonesia Morowali Industrial Park (IMIP), Central Sulawesi. five iso tanks from Balikpapan. Four 20 cubic units from Pertamina in Belawan, North Sumatra. Finally, the capacity of 3 tons of liquid oxygen per day from Krakatau Steel, Cilegon, Banten. Several oxygen producers such as Samator Group, LINDE Indonesia, Petrokimia Gresik, Air Products Indonesia, Air Liquide Indonesia, and Iwatani Industrial Gas Indonesia must maximize their production capacity to supply medical oxygen in Java. The total is 1,315 tons per day. 


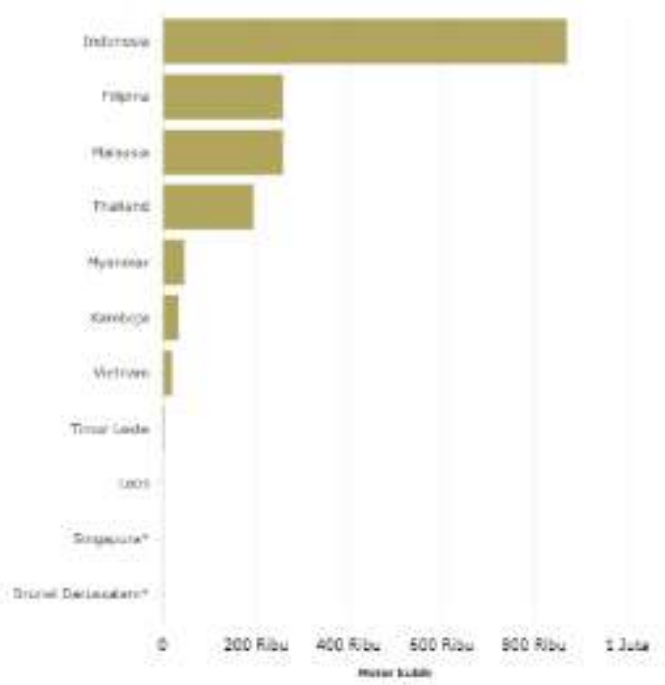

Table. 5

\section{Oxygen Demand in Southeast Asia}

Source:

https://katadata.co.id/safrezifitra/berita/ 60e430cd9601a/kapasitas-hasil-

oksigen-nasional- already-Full-100untuk-medis

The production capacity of oxygen gas in Indonesia until now is around 639.9 thousand tons per year, as much as 300 million tons per year is integrated with users. This production is only equivalent to $74 \%$ of the maximum production capacity of 866 thousand tons per year. Seeing that the national production capacity quantitatively is still sufficient to meet the national needs in the next few weeks, it's just that if the number of COVID-19 patients continues to increase while the national production capacity is limited, it will result in the national medical oxygen supply decreasing, which will cause a national medical oxygen crisis. So the government must immediately anticipate this situation by using all available resources to cut or reduce the spread of COVID-19. The emergency PSBB policy on the island of Java must be implemented properly and optimally because this is a strategy in reducing the positive number of COVID-19 in Indonesia. In addition, the vaccination program must be immediately increased according to the government's target of 180.4 million people, which until June 2021 is still below $20 \%$ of the set target.

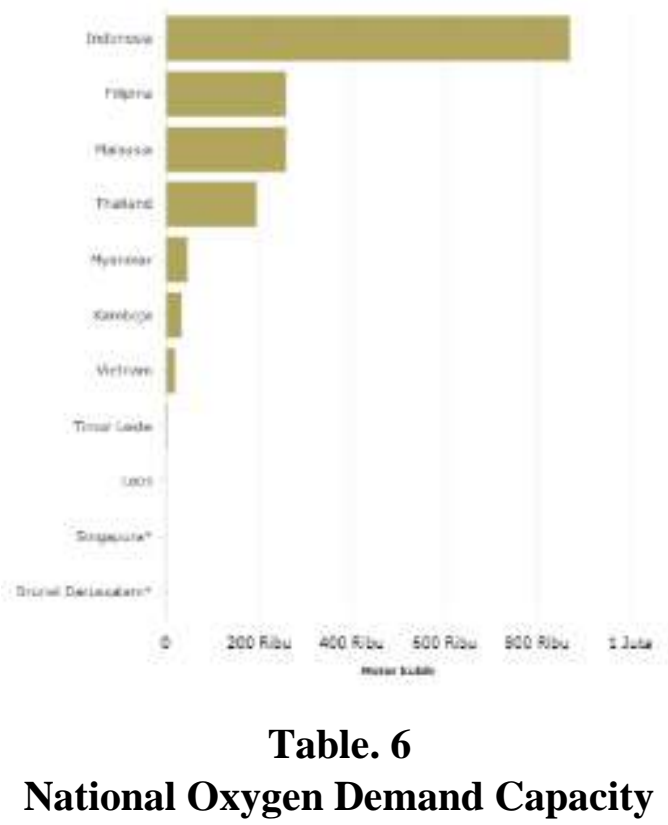

Source:

https://katadata.co.id/safrezifitra/berita/ 60e430cd9601a/kapasitas-hasil-

oksigen-nasional- already-Full-100untuk-medis

In Indonesia, there are nine oxygen factories on the island of Java. A total of four factories in West Java, one factory in Central Java, and the rest in East Java. Based on PATH data, Indonesia needs 124,029 oxygen cylinders measuring 7 cubic meters per day for handling the Covid-19 corona virus as of July 1, 2021. This amount is equivalent to $51.7 \%$ of the total oxygen demand in Southeast Asia. In addition, Indonesia's oxygen demand is the largest in Southeast Asia, surpassing the Philippines and Malaysia. The demand for oxygen per day in the 
two countries reaches 37.1 thousand and 37 thousand cylinders measuring 7 cubic meters per day, respectively.

\section{Limited Health Workers and Health Facilities}

Health workers are at the forefront of dealing with COVID-19. For the past 2 years, health workers have struggled with all their capabilities in dealing with COVID-19 patients. For almost 2 years dealing with the pandemic, the death rate for health workers in Indonesia is one of the highest in the world, of course this will have a negative impact in handling this pandemic because health workers are increasingly limited, inversely proportional to the number of positive cases of covid-19 which is increasing day by day. especially in July 2021, which is the highest number of positive Covid-19 increases per day, which averages 14 thousand people, with a correlation in the direction of the increase in the death ratio, which currently has a ratio of $2.6 \%$, which is one of the highest in the world.

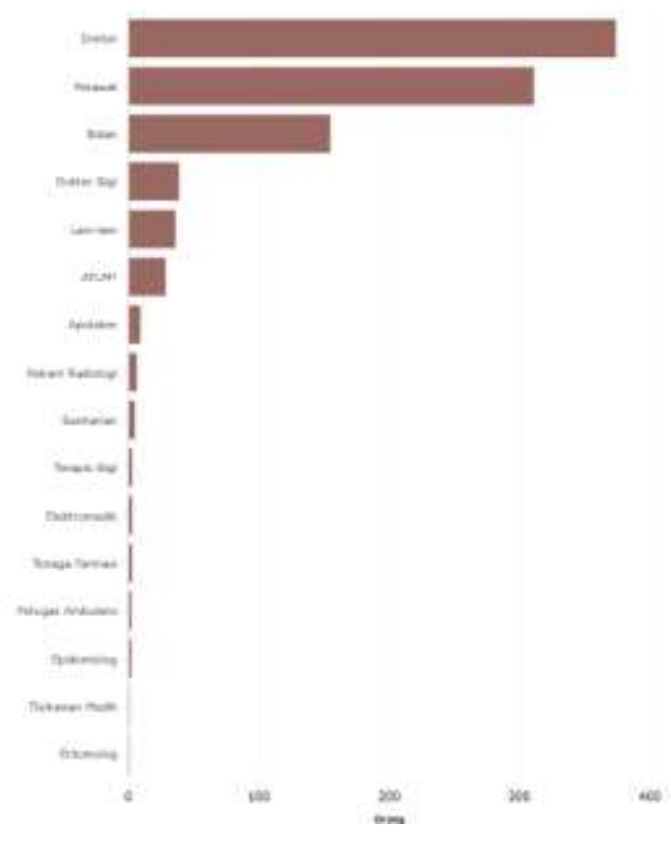

Table. 7

\section{Indonesian Health Workers Mortality Rate}

Source:

https://databoks.katadata.co.id/datapubli sh/2021/06/24/hampir-seribu-energikesehatan-ri-meninggal-hasil-covid-19

The death rate for health workers in Indonesia is one of the highest in the world for 2 years running the covid-19 pandemic has touched almost a thousand health workers who died, they died in carrying out their humanitarian mission to save covid-19 patients in Indonesia. What is very concerning is the number of deaths that occur to specialist doctors who are still limited in number, then second nurses and midwives. The high mortality rate for medical personnel has made the handling in the front lines of this pandemic increasingly limited which resulted in disrupted patient care and treatment. If this is allowed to continue, it will have an impact on patient handling which is getting longer due to the limitations of health workers. Protection of health workers is absolutely necessary, one of which is maintaining working time, working period and level of fatigue, especially at this time the increase in Covid-19 cases has risen sharply so that it will result in an increase in the positive risk of Covid19 which will result in death.

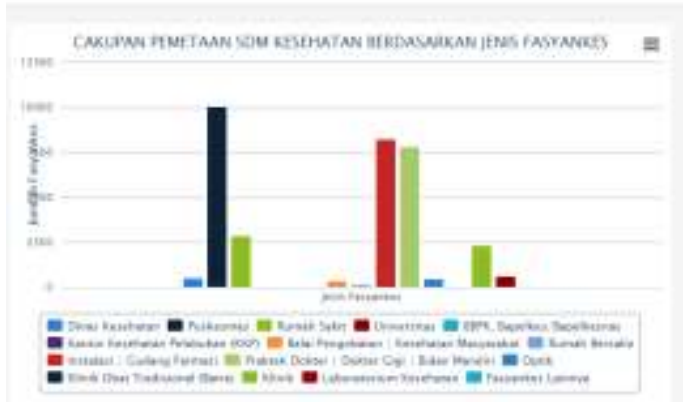

Table. 8 


\section{Health HR by Type of Health Facilities}

Source:

http://bppsdmk.kemkes.go.id/info_sdmk /

A significant increase in COVID-19 cases during June to July 2021 had an impact on the full hospital occupancy rate in handling COVID-19. Health infrastructure distribution is not evenly distributed nationally and is only concentrated on the island of Java. Likewise, modern health facility infrastructure only exists in general on the island of Java. This has resulted in an imbalance in the distribution of health facilities and the handling of patients from the COVID-19 pandemic. while the level of risk of this pandemic has the same ratio level in each area, this will have a negative impact on the handling of COVID-19 in areas that do not yet have health facilities that meet standards.

The national health facilities used so far are public health centers, public hospitals and private hospitals and some use university-owned hospitals. Handling pandemics in sub-districts by using puskesmas facilities, not all of them handle Covid-19 cases, only some are in the country and only a small part can be hospitalized at health centers. If this is allowed, there will be more and more patients who are not treated when the hospital does not accept it and the puskesmas cannot handle it, there will be a humanitarian disaster so that the government in this case the Ministry of Health must immediately increase the capacity of patients for treatment in each hospital. Using a government facility building to be used as an emergency hospital during this pandemic must be done immediately to anticipate the explosion of positive COVID-19 cases, such as at Wisma Atlit Jakarta.

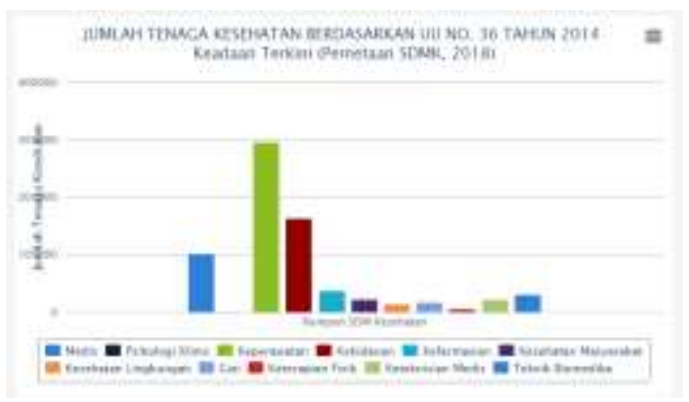

Table. 9

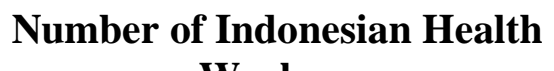
Workers

Source:

http://bppsdmk.kemkes.go.id/info_sdmk I

The number of medical personnel nationally is still limited, judging by the ratio between health workers and the population in Indonesia, so that the Covid-19 case is a major blow to the Health Department. The surge in cases of the Covid-19 pandemic is not followed by sufficient medical personnel, making patient handling impossible quickly and optimally. In addition, the high mortality rate of medical personnel has made the burden of dealing with this pandemic even heavier. The number of doctors in Indonesia is around 100 thousand doctors, nursing staff is 300 thousand, midwifery is 150 thousand and the rest is under 20 thousand so that there is an imbalance compared to the total population of Indonesia. The death of health workers will have a very large impact on handling COVID-19 patients, protection of the safety and health of health workers is absolutely necessary because they are the front line in dealing with COVID-19 cases. 


\section{TELEMEDICINE}

Policies Patients who are confirmed positive for COVID-19 who have no symptoms and have mild symptoms can self-isolate at home or quarantine in a centralized isolation center. The Ministry of Health takes policy steps by ensuring that patients who are selfisolating can continue to receive health services. This health service is in the form of telemedicine, which is a virtual health consultation that can be accessed anytime and anywhere by patients. For the initial stage, this facility is only valid for the capital city of the country and will be continued to other cities nationwide. Positive COVID-19 patients who are self-isolating need consultation, need calm, be cared for, and know that they are receiving the right treatment, so this strategy was carried out due to limited health facilities and the high increase in national Covid-19 positives. So the Ministry of Health provides telemedicine services because if you have to come to the hospital for a consultation with a doctor, it will be difficult and will increase the risk of transmission.

This strategy is by collaborating with 11 telemedicine platforms to provide doctor consultation services and also free drug delivery services.

The 11 telemedicine platforms include;
1. Alodokter,
2. GetWell
3. Good Doctor
4. Hellodoc
5. ClickDoctor
6. ClinicGo
7. Healthy Link
8. Milvik Doctor
9. ProHealth

\section{HealthyQ \\ 11. YesDok}

The doctor will identify the patient based on the results of the consultation, for further treatment based on the patient's condition. Through this service, hospitals can conduct initial screening for patients with moderate/severe symptoms, including the provision of drug packages through pharmaceutical service facilities appointed by the Ministry of Health. The drug package will be sent free of charge to those who are completely asymptomatic, while patients with symptoms, such as a slight fever, will also be given the package for free. Not only that, this telemedicine platform is also integrated with the PCR testing laboratory. For patients who want to do a PCR test, it can be done through the available telemedicine form. Eleven telemedicine platforms are Alodokter, GetWell, Good Doctor and GrabHealth, Halodoc, KlikDokter, and KlinikGo. Then Link Sehat, Milvik Doctor, ProSehat, SehatQ, and YesDok. All of this is given free of charge as a contribution from 11 telemedicine platforms and the medicines are carried out also from the Ministry of Health.

According to the WHO definition, telemedicine (also known as telehealth) is the delivery of health care services by considering distance and using information and communication technology, including: 1) exchange of diagnostic information, 2) treatment and prevention of disease and injury, 3) research and evaluation, and 4) continuing education of health service providers. The demand for telemedicine in Indonesia is quite high, given the unequal distribution of health workers, 
maldistribution of health facilities, and challenging geographical barriers.

An overview of the position of telemedicine in health services in Indonesia. According to him, due to the limited number of doctors in certain places, currently many consultations are carried out through social media such as Whatsapp. Communication in this form is fast, but the poor quality of the documentation demands a new system that is more comprehensive and focuses on the health sector. Telemedicine is present as a solution with four current flagship programs, namely teleradiology, tele-EKG, tele-USG, and teleconsultation. However, it is also possible to develop other programs such as telepathology, teledermatology, and others.

Currently, the Indonesia America Society Academic (IASA) is collaborating with the Papua provincial government in accelerating welfare development in Papua with the support of Bappenas. One form of welfare development in the health sector is by utilizing telemedicine between the Hospital in Papua. It is hoped that by starting from a small scale, telemedicine can continue to develop to integrate education and health services to the provincial and national levels.

Development of telemedicine services at the national level. Given the strategic position of telemedicine in supporting Indonesia's nawacita and e-health, it is proper that its implementation is covered by legal regulations, such as the Minister of Health and the Presidential Instruction. According to the Minister of Health, protected telemedicine services are still limited to teleconsultation and must be carried out between domestic health care facilities. The stages of telemedicine development, starting from the telecardiology and tele-EKG pilot project in 2015, which mostly failed due to signal limitations, then continued with friendin in 2017 with a focus on radiology, ecg, ultrasound and consultation, to the latest development by BPPT in the form of a prototype telemedicine workstation. which can be adopted and adapted by the friends of the Ministry of Health.

The presence of telemedicine can be the answer to easy access to health services. Health service innovations in the internet era help patients use their time more efficiently because they don't have to come to hospitals or health facilities for consultations. Moreover, in the midst of the corona pandemic that has not subsided, patients are strongly advised not to come to the hospital, unless there is an urgent need or an emergency. This appeal appears to prevent the risk of transmission of the corona virus (Covid19).

Quoted from the page of the American Academy of Family Physicians (AAFP), telemedicine is a technology that allows patients to consult doctors privately, without having to meet face to face. Consultation with a doctor helps patients get information about suspected diagnoses, treatment or first treatment in cases of illness or injury, to tips to improve physical health. In several countries of the world, the use of telemedicine technology has been carried out for a long time. However, in Indonesia, this technology has only begun to be commonly used in recent years. With the changing patterns of life in the digital era, many sectors are 
following this development, including health.

\section{The advantages of telemedicine}

The World Health Organization (WHO), has a special division related to the field of digital health. Telemedicine is one of the main outcomes of the development of the health sector in the digital field. According to WHO, there are four things that underlie the existence of telemedicine, namely: Aiming to support clinical care Being a solution to distance and geographical problems in health services Innovation using the latest information technology Improving the quality of life and health of the wider community. In Indonesia, the use of telemedicine is considered to be able to overcome a number of challenges that have been hampering equitable access to health, such as the uneven distribution of health workers, geographical problems, and the lack of health facilities in certain areas. An example of the use of telemedicine that is currently booming in Indonesia is the direct chat feature with doctors that can be done through the application. With this feature, users can freely discuss directly with doctors, anytime and anywhere they are. However, telemedicine still has some limitations. A study published in the journal ABC Cardiol, as reported by the National Institute of Health page, concluded:

\section{Weaknesses of Telemedicine}

The main drawback of telemedicine is that doctors cannot examine patients in person. These limitations certainly affect the quality of diagnosis. The absence of direct physical examinations carried out by doctors to patients makes health workers unable to provide definitive diagnoses through telemedicine. At most, the doctor will only provide a possible diagnosis accompanied by other comparisons. This is understandable, considering the process to establish a diagnosis is a multi-layered step that sometimes also needs to be accompanied by various supporting examinations. However, telemedicine technology may extend to a wider range of features. In addition to making consultations with doctors easier, it is also possible that in the future there will be technology or applications that allow recording of heart rate, blood pressure, and other more complicated tests. Currently, there is already a sensor technology placed on the surface of the skin, to determine the condition of the body systemically.

Technology like this can support the rapid development of telemedicine. Focus on Using Telemedicine Looking at the advantages and disadvantages of telemedicine, it is legitimate to say that this feature cannot be a universal solution to health care problems for the community. Therefore, WHO recommends several focuses that can be done in the use of telemedicine services. First, as a means of technology to facilitate treatment control, such as answering questions about the treatment that is being or has been completed by the patient. Second, to make it easier for patients to know the exact laboratory results, especially if all the results read normal. Third, providing access to be able to communicate with health workers from hard-to-reach places. Fourth, make it easier for patients to gain knowledge about simple medical procedures that can be done at home, such as first aid when diarrhea or injury.

Fifth, provide advice on medical specialties that match the health 
problems that the patient is currently experiencing. For example, providing advice about dentistry specialties, or pediatric subspecialties. Sixth, cutting

queues at health facilities and making services to patients more efficient. Although there are still pros and cons to this feature, telemedicine is a technological development that cannot be avoided. Regulations from the side of doctors and users are still being discussed, to find a middle way that can benefit both parties. In the future, the use of telemedicine services will continue to be designed not to replace visits to doctors, but as a companion to treatment that is getting better, more efficient, and of course appropriate.

\section{BIBLIOGRAPHY}

https://covid19.go.id/peta-sebarancovid19

https://www.kemkes.go.id/article/view/ 21051100001/anticipation-lonjakancase-pasca- Lebaran-kemenkes-addkapasitas-place-tidur-rs.html https://katadata.co.id/safrezifitra/berita/ 60e430cd9601a/kapasitas-hasiloksigen-nasional- already-Full-100untuk-medis https://katadata.co.id/safrezifitra/berita/ 60e430cd9601a/kapasitas-hasiloksigen-nasional- already-Full-100untuk-medis https://databoks.katadata.co.id/datapubli sh/2021/06/24/hampir-seribu-energikesehatan-ri-meninggal-hasil-covid-19 http://bppsdmk.kemkes.go.id/info_sdmk I 